http://jmscr.igmpublication.org/home/ ISSN (e)-2347-176x ISSN (p) 2455-0450 crossref DOI: https://dx.doi.org/10.18535/jmscr/v7i7.80

Journal Of Medical Science And Clinical Research

\title{
The Outcome of Total Mesorectal Excision (TME) for the Management of Rectal Cancer
}

Authors

\section{Dr Mahboobur Rahman ${ }^{1 *}$, Dr Md. Abdul Hadi ${ }^{2}$, Dr Md. Abul Kalam Azar ${ }^{3}$,} Dr Md. Masud Sattar ${ }^{4}$, Dr Sabina Parveen ${ }^{5}$, Dr Md. Mahmudur Rahman6

${ }^{1}$ MS (Surgery), Senior Consultant (Surgery), 250 Bedded District Hospital, Kishoreganj

${ }^{2}$ MS (Surgery), Senior Consultant (Surgery), 100 Bedded Sadar Hospital, Lalmonirhat

${ }^{3}$ MS (Surgery), Assistant Professor, Department of Surgery, Shaheed Ziaur Rahman Medical College

Hospital, Bogra

${ }^{4}$ MS (Surgery), Assistant Professor, Department of Surgery, Khulna Medical College, Khulna

${ }^{5}$ Assistant Professor, Department of Gynae \& Obs.,US- Bangla Medical College \& Hospital, Rupganj,

Narayanganj, Dhaka, Bangladesh

${ }^{6}$ Deputy Director (CS) \& Program Manager (SD), CCSPD, Directorate, General of Family Planning,

Karwan Bazar, Dhaka, Bangladesh

*Corresponding Author

Dr Mahboobur Rahman

MS (Surgery), Senior Consultant (Surgery), 250 Bedded District Hospital, Kishoreganj

\section{Abstract}

Background: Now a day's total mesorectal excision (TME). is use as a gold standard technique for middle and lower third of non-disseminated rectal cancer.

Objective: In this study our main aim is to estimate the outcome of total TME for the the management of rectal cancer.

Method: This quasi experimental study was done at The department of General Surgery and Colorectal unit of Bangabandhu Sheikh Mujib Medical University (BSMMU), Dhaka and Somorita Hospital, Dhaka from July 2005 to June 2007 where patients who having carcinoma involving the middle and lower third of the rectum were evaluated.During the study patients were divided into two groups: Group A: Patients undergone total mesorectal excision (TME) and Group B: Patients undergone conventional operative method. All patients were operated under general anesthesia, placed in Lloyd-Davies position.

Result: in the study one (1.9\%) patient of group B received pre-operative chemotherapy. 52 (98.1\%) patients of TME: group and similar number patients of Conventional group were received chemotherapy postoperatively. Also, in group A, pelvic pain was present in (5.7\%) patient, per rectal bleeding in (1.9\%), stomal bleeding (1.9\%) and thromboembolic complication in (1.9\%) patient. In group B, pelvic pain was in (20.8\%) patients, vomiting in (3.8\%), thromboembolic complication in (1.9\%), wound infection, in (1.9\%) patients.

Conclusion: From our result, we can say that total mesorectal excision (TML) is an effective and appropriate operative procedure for the management of middle and lower third of rectal cancer than the conventional technique.

Keyword: Total mesorectal excision (TME), Rectal cancer, Conventional technique. 


\section{Introduction}

The rectum which is the last 6 inches of the large intestine (colon). Rectal cancer rises from the lining of the rectum. In 2012, more than 40,000 people in the United States will be spotted with colorectal cancer, making it the most common cancer in both men and women. About $5 \%$ of Americans will progress colorectal cancer during their lifetimes. Colorectal cancer is highly curable if detected in the early stages. ${ }^{[1]}$

The majority of rectal cancers are treated by cither anterior resection (removal of the upper rectum with anastomosis of the colon to the rectal stump) or abdominal perinatalexcision of the rectum (complete excision of the rectum and anal canal with permanent end colostomy).

Local recurrence after surgery for rectal cancer is a disaster for the patient. Cure at this stage is seldom possible and the disease often takes a prolonged and excruciating course. ${ }^{[2]}$

Local recurrence can be defined as a clinically or radio logically suspected or biopsy-confirmed tumor in the pelvis, alone or in the presence of newly diagnosed distant metastasis. Eighty per cent of all local recurrence develops within two years following surgery and they are very difficult to treat. The patient of local recurrence often presents with persistent pelvic pain, may radiate down to the leg if sacral roots involved. Bladder problem may occur. If recurrence developed after abdominal perineal excision, a swelling or induration may be present in the perineum, or an abscess or discharging sinus may develop. Occasionally, a large local recurrence in the pelvis may lead to bilateral leg edema by pressure or invasion of lymphatic or veins.

Over the past two decades, a fundamental changes in operative technique has taken place. Conventional surgery has given way to sharp dissection along definable planes. The technique known as total mesorectal excision (TME) or complete circumferential mcsorcctal excision (CCME), produce the complete resection of an intact package of the rectum and its surrounding mesorectum to the level of the pelvic floor with a negative distal margin enveloped within the visceral pelvic fascia with uninvolved circumferential margins by sharp dissection along avascular plane (holy plan) between the parietal and visceral fascia under direct vision. ${ }^{[3][4][5]}$ Total mesorectal excision cures carcinoma of the rectum, local recurrence can be reduce less than $5 \%{ }^{[6]}$ and provides excellent local control through resection of the entire unit of regional spread that is excised, intact and with negative circumferential margin and it also compatible with autonomic nerve preservation and with sphincter preservation. ${ }^{[3]}$ Here mesorectum is the perirectal tissue composed of fat, lymphatic and blood vessels contained within the endo-pelvic visceral fascia md extending the length of the rectum.

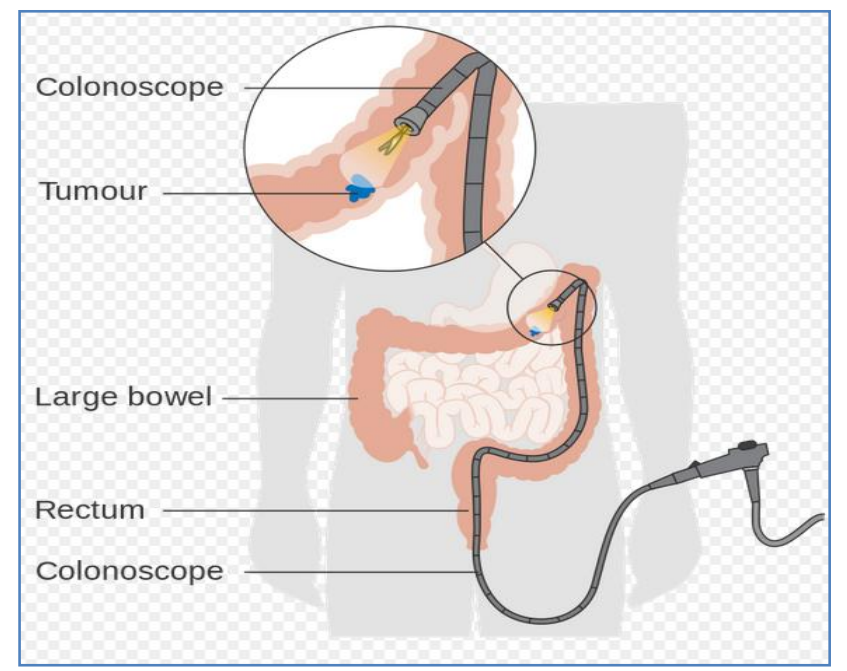

Figure-1: Local resection of early stage colon cancer

In this study our main objective is to estimate the outcome of total TME for the management of rectal cancer.

\section{Objective}

\section{General Objective}

$>$ To estimate the outcome of total TME for the management of rectal cancer.

\section{Specific Objective}

$>$ To identify pre and post-operative adjuvant therapy of the patients

$>$ To detect distance of lesion and type of operation. 
Methodology

Study type

This was a quasi-experimental study

Place and period of the study

This study was conducted at The department of General Surgery and Colorectal unit of Bangabandhu Sheikh Mujib Medical University (BSMMU), Dhaka and Somorita Hospital, Dhaka from July 2005 to June 2007 where patients who having carcinoma involving the middle and lower third of the rectum were evaluated.

\section{Sampling Technique}

$>$ During the study sampling technique was purposive.

\section{Sample Size}

$>$ According to this formula:

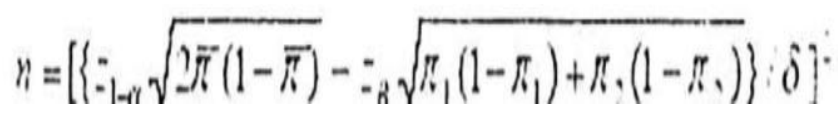

Sample size will be 640 in each group. The study involves follow up of the patients and considering the chances of some drop out then additional $10 \%$ of the required sample should be taken which will be additional 64 patients giving rise to a total member of patients 704 in each group. But due to non-availability of resources such as manpower, logistic support, financial support \& also time constraint, my sample size was 106. Among them 53 patients underwent total mesorectal excision (TME) and another 53 patient's underwent conventional technique.

\section{Inclusion Criteria}

$>$ Histologically proved rectal carcinoma of middle or lower third of rectum after colonoscopy/excision biopsy.

$>$ Disease stage-DUKE- A or B or C1

$>$ Mobile tumor

$>$ Middle \&/or lower third involvement of rectal cancer

$>$ Resection performed by laparotomy.

\section{Exclusion Criteria}

$>$ Patients, who refused to be included in the study
$>$ Evidence of distant metastasis by clinical or radiographic examinations.

$>$ Presence of concurrent other malignant diseases

$>$ Follow-up was not achievable.

\section{Method}

Informed consent was taken from each patient in the consent form after they were properly informed about the treatment procedure, expected results and possible complications. Detailed history was taken, clinical examination and proper investigations was done for each patient and was recorded in pre-designed data collection sheet. During the study patients were divided into two groups: Group A: Patients undergone TME and Group B :Patients undergone conventional operative method.

All patients were operated under general anesthesia, placed in Lloyd- Davies position. Following two techniques were used:

- One was total mesorectal excision (TME), which demands sharp meticulous dissection along avascular plane immediately adjacent to the mesorectum, under direct vision.

- Another was conventional operative procedure, in which blunt dissection was done without direct vision and usually performed by surgeons who are not familial to total mesorectal excision (TME).

Routine follow-up evaluations in this study were conducted at 3 months, at 6 months and at 12 months interval from the date of primary operation. All patients were advice to come in BSMMU, department of surgery, for follow up according to the above time schedule. They were also advice to come whenever they develop any complications. Each follow up was including history, physical examination and relevant investigations, such as USG of whole abdomen or CT scan of abdomen if recurrence suspect, chest $\mathrm{X}$-ray, bone X- ray or isotope bone scan, serum CEA level, sigmoidoscopic or colonoscopy biopsy etc. 


\section{Statistical analysis}

Statistical analyses of the results were obtained by using window based computer software devised with Statistical Packages for Social Sciences (SPSS-13) (SPSS Inc, Chicago, IL, USA). All the relevant collected data were compiled on a master chart first. The results were presented in tables. Figures. Diagrams. Percentages were calculated to find out proportion of the findings. Statistical analyses were done by using appropriate procedure like chi square test, student $t$ test where applicable. Statistical significance is set at 0.05 level and confidence interval at $95 \%$ level.

\section{Results}

In table-1 shows age distributions of the patients where the mean age $( \pm S D)$ of Group-A and Group-B were $38.21 \pm 13.58$ and $38.04 \pm 64$ years respectively. The following table is given below in detail:

Table-1: Age distributions of the patients.

\begin{tabular}{lcccc}
\hline Age (year) & $\begin{array}{c}\text { Group A } \\
(\text { TME, n=53) }\end{array}$ & $\begin{array}{c}\text { Group B } \\
(\text { Conventional, n=53) }\end{array}$ & $\begin{array}{c}\text { t value (df) } \\
\text { P } \\
\text { value* }\end{array}$ & \\
$21-30$ & $4(7.5) \#$ & $1(1.9)$ & & \\
$31-40$ & $15(28.3)$ & $17(32.1)$ & & \\
$41-50$ & $14(26.4)$ & $14(26.4)$ & & \\
$51-60$ & $11(20.8)$ & $14(26.4)$ & & \\
$61>$ & $6(11.3)$ & $6(11.3)$ & & \\
Total & $3(5.7)$ & $1(1.9)$ & & \\
\hline Mean \pm SD & $38.21 \pm 13.58$ & $38.04 \pm 11.64$ & $0.069(104)$ & 0.945 \\
Range & $15-70$ & $20-70$ & & \\
\hline
\end{tabular}

In figure-2 shows gender distributions of the patients where $46.7 \%$ patients of Group-A and $56.6 \%$ of Group-B were males. The rest $52.8 \%$ of Group-A and $43.4 \%$ of Group-B were females. The following figure is given below in detail:

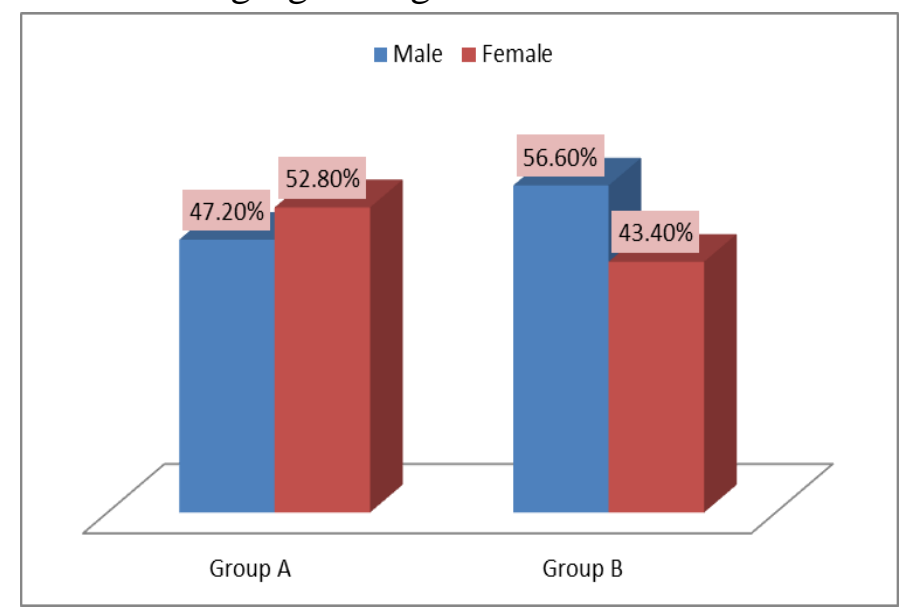

Figure-2: Gender distributions of the patients.

In table-2 shows pre and post-operative adjuvant therapy of the patients in both groups where One (1.9\%) patient of group B received pre-operative chemotherapy. $52(98.1 \%)$ patients of TMI: group and similar number patients of Conventional group were received chemotherapy postoperatively. The following table is given below in detail:

Table-2: Pre and post-operative adjuvant therapy of the patients in both groups

\begin{tabular}{|l|c|c|}
\hline Time/type of therapy & $\begin{array}{c}\text { Group A } \\
\text { (TME) }\end{array}$ & $\begin{array}{c}\text { Group B } \\
\text { (Conventional) }\end{array}$ \\
\hline Pre-operative chemotherapy & $0(.0)$ & $1(1.9)$ \\
\hline $\begin{array}{l}\text { Post-operative chemotherapy } \\
\text { chemotherapy }\end{array}$ & $52(98.1)$ & $52(98.1)$ \\
\hline Preoperative radiotherapy & $0(.0)$ & $0(.0)$ \\
\hline Postoperative radiotherapy & $1(1.9)$ & $0(.0)$ \\
\hline
\end{tabular}

In table-3 shows duration of the post-operative hospital stay of both groups where in Group-A and Group-B were $14.5 \mathrm{~S}(\bullet 2.98)$ and $1(>.42( \pm$ $6.64)$ days respectively. No significant difference was observed between groups with respect to duration of post-operative hospital stay ( $\mathrm{p}>0.05$ ). The following table is given below in detail:

Table-3: Duration of the post-operative hospital stay of both groups

\begin{tabular}{|l|c|c|c|c|}
\hline Hospital stay & $\begin{array}{c}\text { Group A } \\
\text { (TIME, }\end{array}$ & $\begin{array}{c}\text { Group B } \\
\text { (Conventiona, }\end{array}$ & t & P value \\
\cline { 1 - 3 } Mean \pm SD & $14.58+2.98$ & $16.42 \pm 6.64$ & 1.83 & 0.07 \\
\cline { 1 - 3 } Range & $1-20$ & $9-57$ & & \\
\hline
\end{tabular}


In figure-3 shows the operation in relation to distance from the analverge of both groups where Maximum respondents of group A, 25 (47.2), were undergone ULAR followed by low anterior resection (LAR) $34.0 \%$ and APR 18.9\%. Maximum respondents of group 13, were undergone abdomino-perineal resection (APR). 92.5\% of APR followed by LAR $3.8 \%$ and anterior resection (AR) $3.8 \%$. the following figure is given below in detail:

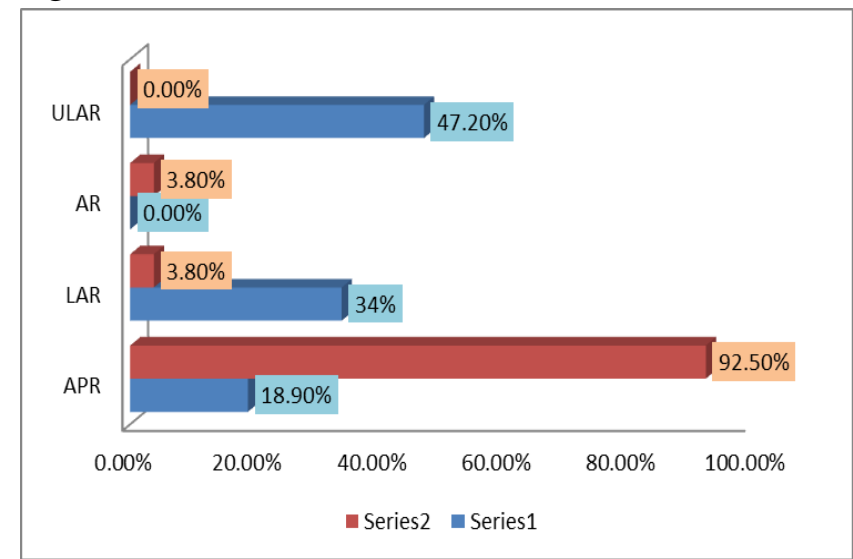

Figure-3: The operation in relation to distance from the anal verge of both groups.

In table-4 shows distribution of the patients of both group by distance of lesion and type of operation where in group A, within 3 to $5 \mathrm{~cm}$ distance from anal verge. $23(92.0 \%)$ patients were undergone ULAR and $2(8.0 \%)$ patients LAR. In group B within same distance 29 $(100.0 \%)$ patients were undergone APR. Lesions below $3 \mathrm{~cm}$ distance from anal verge, $10(83.3 \%)$ patients of group A were undergone APR and 2 $(8.0 \%)$ patients ULAR but in group B within same distance .all, 3 (100.0\%), patients tinder gone APR. Lesions more than $5 \mathrm{~cm}$ distal to anal verge of all patients of group A were undergone LAR and with same distance in group B, 17 (81.0\%) patients were undergone APR, 2 patients LAR and 2 patients ULAR. The following table is given below in detail:

Table-4: Distribution of the patients of both group by distance of lesion and type of operation.

\begin{tabular}{l|c|c|cc|cc|}
\hline $\begin{array}{l}\text { Name of } \\
\text { operation }\end{array}$ & \multicolumn{6}{|c|}{ Distance and types of operation } \\
& $\mathrm{GrA}$ & $\mathrm{GrB}$ & $\mathrm{GrA}$ & $\mathrm{Gr}-\mathbf{c m}$ & $\mathrm{GrA}$ & $\mathbf{5} \mathbf{c m}$ \\
& $10(83.3)^{*}$ & $3(100.0)$ & $0(.0)$ & $29(100.0)$ & $0(.0)$ & $17(81.0)$ \\
APR & $0(.0)$ & $0(.0)$ & $2(8.0)$ & $0(.0)$ & $16(100.0)$ & $2(3.8)$ \\
\hline LAR & $2(8.0)$ & $0(.0)$ & $23(92.0)$ & $0(.0)$ & $0(.0)$ & $2(3.8)$ \\
\hline ULAR &
\end{tabular}

In figure-4 shows distribution of patients according to distal metastasis where in group A. no patient had distal metastasis but in group B $3.77 \%$ patients had distal metastasis. The following figure is given below in detail:

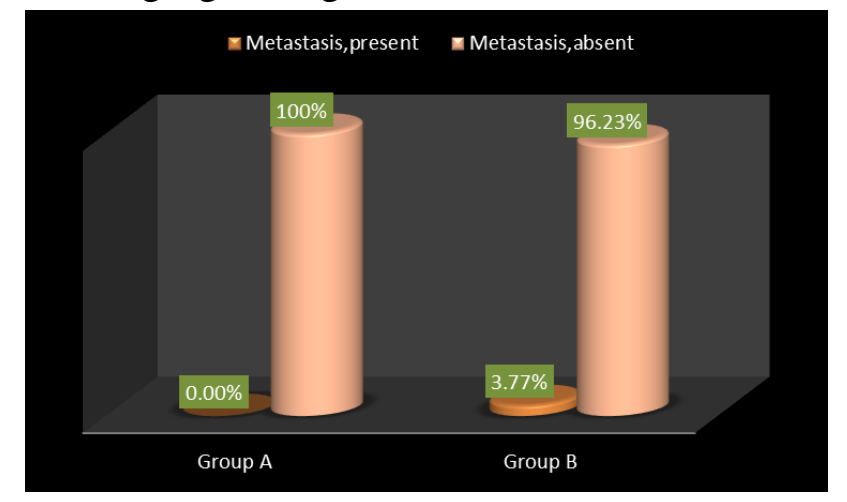

Figure-4: Distribution of patients according to distal metastasis.

In figure-5 shows post-operative complication of the patients where in group A, pelvic pain was present in $(5.7 \%)$ patient, per rectal bleeding in (1.9\%), stomal bleeding (1.9\%) and thromboembolic complication in $(1.9 \%)$ patient. In group B, pelvic pain was in $(20.8 \%)$ patients, vomiting in $(3.8 \%)$, thromboembolic complication in $(1.9 \%)$, wound infection, in $(1.9 \%)$ patients. The following figure is given below in detail:

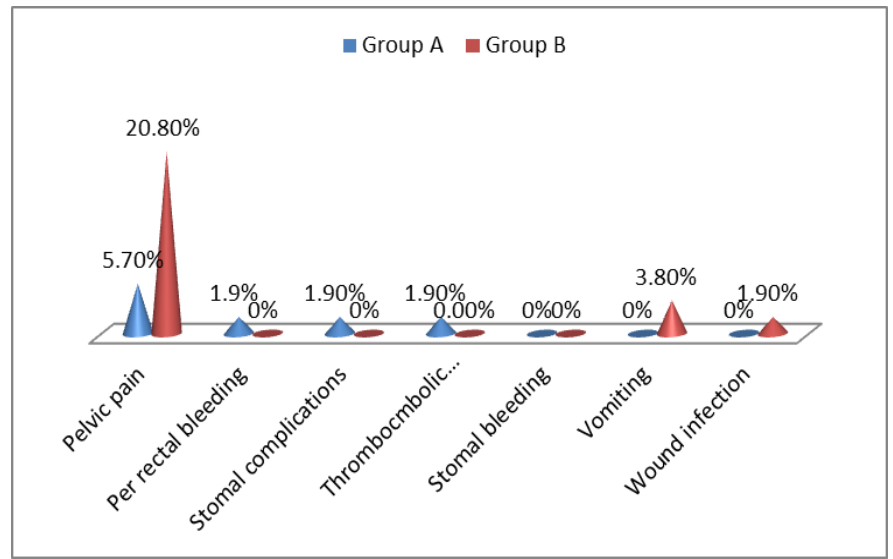

Figure 5: Post-operative complication of the patients

\section{Discussion}

In this study patients were divided into two groups. 53 patients treated by total mesorectal excision (TME) were in group-A and another 53 patients treated by conventional method were in group-B. 
Mean age of group A was $38.21 * 13.58$ years and in group B was 38.04 \pm 11.64 years. Mean age and sex as also statistically insignificant in similar type of one study. ${ }^{[6]}$.Ratio of male and female patients of our study was 1.1: 1 .

With regard to the enhanced access to and use of screening and average treatment, overall occurrence rate has reduced by about $3 \%$ per year during the past decade. Though a large drop in the number of rectal cancers has been establish in adults aged 65 and older $(-1.5 \%$ for $50-64$ years and $4.3 \%$ for ages above 65 ), this rate has enlarged by $1.8 \%$ yearly for rectal cancers among adults younger than 50 years. In disparity to proximal and distal colon cancers, the median age at diagnosis for rectal cancer is younger (63 years in men and 65 years in women). There is also a momentous variation in tumor location by age, with a notable reduction in rectal tumors in older age. Male to female frequency rate ratio for rectal cancers also varies among diverse age groups as follows: 1.10 for 0-49 years, 1.19 for 50-64 years, 1.27 for $50-79$ years, and 1.29 for those 80 years and older. ${ }^{[7]}$

Location of tumor (third) was important because of total mesorectal excision (TME) was performed in middle or lower third of rectal tumor. ${ }^{[8]}$ In case of upper third rectal tumormesorectal excision is performed only up to $5 \mathrm{~cm}$ distally from the lower end of tumor, which is actually a partial mesorectal excision. ${ }^{[9]}$ According to the Cancer Registry of Norway; i.e. $7 \mathrm{~cm}$ or less from the anal verge, low rectum; over $7 \mathrm{~cm}$ but less than or equal to $12 \mathrm{~cm}$, mid rectum; over $12 \mathrm{~cm}$ but less than or equal to $20 \mathrm{~cm}$, upper rectum. ${ }^{[10]}$

In this study, regarding post-operative hospital stay, mean duration of group A and group B were $14.58( \pm 2.98)$ and $16.42( \pm 6.64)$ days respectively. No significant difference was observed between groups with respect to duration of post-operative hospital stay $(\mathrm{p}>0.05)$.

In the present series no patient had distal metastasis in group A, but in group B, 2 (3.77\%) patients had distal metastasis. No significant difference was observed between groups in terms of distal metastasis ( $\mathrm{p}>0.05)$.

In group A, pelvic pain was present in $3(5.7 \%)$ patient, per rectal bleeding in $1(1.9 \%)$, stomal bleeding $1 \quad(1.9 \%)$ and thromboembolic complication in 1 (1.9\%) patient. In group B, pelvic pain was in $11(20.8 \%)$ patients, vomiting in $2(3.8 \%)$, thromboembolic complication in 1 $(1.9 \%)$. wound infection in $1(1.9 \%)$ patients. Significant test could not be performed as whole cells of a row contain 0 values.

\section{Conclusion}

After much analysis we can say that total mesorectal excision (TME) is an effective and appropriate operative procedure for the management of middle and lower third of rectal cancer than the conventional technique.

\section{Reference}

1. Arbman G, Nilsson E, Hallbook O, Sjodahl R, 1996, 'Local recurrence following total mesorectalcxcision for rectal cancer', British Journal of Surgery, vol. 83, pp. 375-379.

2. Enker WE, Thaler HT, Cranor ML, Polyak T, 1995, 'Total mcsorectal excision is the operative treatment of carcinoma of the rectum', J Am Coll Surg. vol. 181, no. 4, pp. 335-46.

3. Kapiteijn E, van de Velde CJFI, 2000, 'European trials with Total Mesorectal Excision', Scm Surg Oncol, vol. 19, pp. 350-357.

4. Maurer CA, Z'gragger K, Renzulli P, Schilling MK, NetzerP,Butchler MW,2001 'Total mesorectal excision preserves male genital function compared with conventional rectal cancer surgery', British Journal of Surgery, vol. 88, pp. 1501-1505.

5. Russell RCG, Norman SW, 2004, Bailey \& Loves Short Practice of Surgery, $24^{\text {th }}$ edn, Arnold, London,

6. Carlsen E, Schlichting E, Guldvog I, Johnson E, Mcald RJ, 1998, 'Effect of the 
introduction of total mesorectal excision for the treatment of rectal cancer', British Journal of Surgery, vol. 85, pp. 526-529.

7. Beets-Tan RG, Beets GL. Rectal cancer: review with emphasis on MR imaging. Radiology. 2004 Aug;232(2):335-46.

8. Ridgway PF, Dorzi AW, 2003, 'The role of total mesorectal excision in the management of rcctal cancer', Cancer Control, vol. 10, no. 3, pp. 205-11.

9. Wibe A, Rcndcdal PR, Svensson E, Norstcin J, Hide TJ, Myrvold III-', cl a I,2002,'Prognostic significance of the circumferential resection margin following total mesorectal excision for rectal cancer', British Journal (\}f Surgery, vol. 89, pp. 327-334.

10. Morgan AF, Finly IG, 2000, 'Preoperative staging of rectal cancer allows selection of patients for preopcrativc radiotherapy', British Journal of Surgery vol. 37, pp. 575579. 